\title{
An In-Vitro Comparison and Analysis of Apical Microleakage of Thermafil, System B and Cold Lateral Compaction Obturation Techniques by using Linear Dye Penetration Measurement Method
}

\author{
Noor-ul-Ain Jawaed, Syed Yawar Ali Abidi, Muhammad Imran Khan Niazi, Khurram Parvez, \\ Farah Naz, Shahbaz Ahmed
}

\begin{abstract}
OBJECTIVE: To evaluate and compare the apical microleakage of Thermafil and System $B$ in comparison with cold lateral compaction (CLC) endodontic obturation technique using dye penetration measurement.

METHODOLOGY: This in vitro experimental study was conducted from January to June 2014 at the Department of Operative Dentistry. Total 244 extracted human maxillary and mandibular single rooted teeth with intact roots were selected and divided into 3 groups according to obturation method: Group A, carrier based thermo-mechanical compaction (Thermafil); Group B, warm vertical compaction (System B); and Group C, cold lateral compaction (CLC).

Protaper universal rotary system (X-Smart) up to file size F3 used to prepare the root canals. $5.25 \%$ Sodium hypochlorite $(\mathrm{NaOCl})$ and $17 \%$ Ethylenediamine tetra-acetic acid (EDTA) used to irrigate the canals. Samples were engrossed in $2 \%$ methylene blue and stored at $37 \mathrm{C}^{\circ}$ for 7 days. The root of each tooth was sectioned, and linear dye leakage (LDL) was measured by stereomicroscope.

RESULTS: SPSS version 16 was utilized for statistical analysis. To compare the means, Bonferroni test-one-way analysis of variance was performed. For different groups means with standard deviation (SD) of dye penetration were noted as follows: Group A $2.02 \mathrm{~mm}$ (SD \pm 0.86 ), Group B $2.17 \mathrm{~mm}(S D \pm 0.90)$ and Group $C 2.67 \mathrm{~mm}(S D \pm 1.17)$. The difference between group $A$ and $B$ was statistically insignificant $(p=0.586)$ however in comparison to group $C$ it was significant $(p=0.000)$. Grade 5 dye penetration was noted in very few cases $(12.8 \%)$ in group $C$.

CONCLUSION: Leakage found in all the specimens. However, roots obturated with cold lateral condensation leaked the most while Thermafil exhibited least leakage.
\end{abstract}

KEYWORDS: Protaper, System B, Thermafil and Cold lateral compaction

This article may be cited as: Jawaed N, Abidi SYA, Niazi MIK, Parvez K, Naz F, Ahmed S. An In-Vitro Comparison and Analysis of Apical Microleakage of Thermafil, System B and Cold Lateral Compaction Obturation Techniques by using Linear Dye Penetration Measurement Method. J Liaquat Uni Med Health Sci. 2020;19 (02):133-8. doi: 10.22442/jlumhs.201920676

\section{INTRODUCTION}

Complete sealing of the root canal system (RCS) is required to achieve a successful root canal therapy (RCT). Studies have indicated that most filling materials are unable to fill the canal system in all dimensions. According to Ingle, $59 \%$ of RCT failures are related to leakage following insufficient quality and quantity of obturation of RCS ${ }^{1}$. As a result, several obturation techniques have been developed to enhance the quality of coronal andapid seal $^{2,3}$. Studies have shown that the popular cold lateral compaction obturation technique does not provide the completely sealed apices ${ }^{4}$. CLC resulted in a non-homogeneous mass of GP pressed together and held together by friction and luting sealer resulting in voids in final obturation. CLC also depends on the sealer to fill the accessory canals and results in disproportionate amounts of sealer which can resorb over time ${ }^{4}$. Studies have shown that heat softened GP can better fill the RCS by replicating the intricacies of the RCS and seeping into the RCS irregularities. There is various heat softened GP obturation techniques such as, warm lateral condensation (WLC), vertical condensation (VC), coated carrier system (CCS), injection and thermo mechanical condensation ${ }^{4}$. The Thermafil (TF) obturation was founded by Johnson in 1987, where alpha phase gutta-percha was heated on the metallic carrier to fill the $\mathrm{RCS}^{4-8}$. He believed that this technique would accomplish complete sealing of the root canals.

Continuous wave compaction obturation technique 
is claimed to be quick and simplifies the obturation of the RCS. System B sufficiently achieved good quality of apical seal in in-vitro studies ${ }^{4}$. Despite the requirement of down pack followed by backfill, this obturation technique is meant to be simpler than the vertical condensation ${ }^{4,5}$.

To date no obturation material is found which can ensure the entire prerequisite to completely seal the RCS. Microleakage of the apical half remains the most common finding in root treated teeth raising interest related to the standard of obturation provided by the latest available root canal obturation materials. The aim of this in-vitro study was to compare the quality of TF, System B and CLC obturation techniques to seal the root canal apices. Hypothesis of the study is that there is no difference in microleakage of the apical seal obtained by different conventional and thermoplastic root canal obturation techniques.

\section{METHODOLOGY}

This In-vitro experimental study was performed at the Department of Operative Dentistry of Dr. Ishratul-Ebad khan institute of oral and health sciences (DIKIOHS) Dow University of health Sciences from January to June 2014. Microscopic assessment was performed in the department of Materials Engineering, NED University Karachi, Pakistan. Extracted teeth were collected from department of oral and maxillofacial surgery (DIKOHS, DUHS) by convenience sampling technique.

\section{Sample size estimation}

244 maxillary and mandibular single rooted permanent teeth were extracted. By considering Kytridou V $1999^{9}$ work, Group A $(\mathrm{m}=1.45 \pm 0.94)$, Group B $(m=1.86 \pm 6.8)$. Least of difference $=0.4$. Power of the study $=30 \%$. By keeping Margin of error as $5 \%$ and level of significance as $10 \%$, the sample size was calculated as 234 which was increased to $244(n=78$, in each experimental group and $n=5$ in each control group).

\section{Data Collection}

Permanent single rooted teeth from both genders and jaws that were extracted as a part of orthodontic treatment planning and due to periodontal disease. All the Teeth with were radiographed on the buccal and proximal view for the single root canal and mature apex and were included. The following teeth that exhibited any of the following conditions on visual and radiographic evaluation were excluded; Fractures, cracks, completely calcified canals, root resroption (internal, external), grossly carious teeth including root caries, teeth with multiple roots and curved root canals.

\section{Sample Preparation}

Ultrasonic scalers (U/S) were used to remove debris (soft and hard). Access cavities were made using a high-speed hand piece under air-water spray and diamond burs under copious water cooling $(80 \mathrm{~mm}$ diamond, Komet, Lemgo, Germany). Radiographic working lengths (WL) were taken using ISO size $15 \mathrm{~K}$ hand files (Mani, Japan) until the files passed the apical foramen $1 \mathrm{~mm}$ was then subtracted from it. Teeth samples were stored in normal saline.

Protaper Universal nickel-titanium files(Ni-Ti) were used to prepare the canals to finishing file size F3 (crown down technique) (Dentsply, Maillefer). $5 \mathrm{ml}$ of $5.25 \%$ Sodium hypochlorite (NaOCl-Sultan Healthcare) using a 27-gauge endodontic irrigation tip was used for irrigate in between filing. Ethylenedi -aminetetra-acetic acid (EDTA) $17 \%$ gel (Dent Wash, Prime Dental Products) was used as a final irrigant. Sterile paper points (PP) were used to dry the canals (K-Dent Co, Korea). Samples were divided into 3 groups $(n=78)$ and one control groups $(n=5)$. AH Plus sealer (Dentsply, Maillefer) was used as a sealant for all obturation techniques.

\section{Group A ( $n=78)$}

In this group, obturation of the canals was done using the plastic carrier based Thermafil (Dentsply, Maillefer, Switzerland). Therma-prep oven was used for heating the Thermafil for a minimum of 15-45 seconds to the size matching the verifier. It was then gently introduced into the canals within $0.5 \mathrm{~mm}$ of the WL. After cooling, extra plastic material was removed using a high-speed round bur.

\section{Group $B(n=78)$}

Teeth in this group were obturated using the System B technique (Analytic, Sybron Dental Specialties, CA, USA). F3 taper 30/09 size gutta-percha cones were placed within $0.5 \mathrm{~mm}$ of

the WL. A medium-large tip bound in the canal $3 \mathrm{~mm}$ from the WL was used for obturation. The unit was pre-set to $200^{\circ} \mathrm{C}$ during apical condensation of the primary GP (down-pack). The Obtura Max system (Sybron Endo) used for the back-fill with the temperature set at $185^{\circ} \mathrm{C}$.

\section{Group $C(n=78)$}

Standard CLC technique was used for obturation in this group. A master cone of standardized ISO No. 30 GP coated with $\mathrm{AH}$ Plus sealer (K-Dent Co, Korea) was obturated up to the WL. Accessory GP were inserted after lateral spreading with finger spreaders (Mani, Japan) until the canal was filled.

Quality of obturation was determined by taking endodontic periapical radiographs (PA) (Kodak) from different aspects of each tooth (mesial and buccal). Teeth with questionable obturation radiographically were re-obturated. The access cavities were filled with Ketac Molar (3M, ESPE). 
Normal saline (Shanxi Shugang Pharmaceutical Co., Ltd) was used to store the specimens and then placed in an incubator (Memart, Germany) for 24 hours in $100 \%$ humidity at $37^{\circ} \mathrm{C}$ for the $\mathrm{AH}$ plus sealer to set.

\section{Positive control $(n=5)$}

The samples were instrumented and left un-obturated. This was done to prove that leakage testing would prevent the dye penetration (DP) except for the apical areas in the prepared and un-obturated canals.

\section{Negative control $(n=5)$}

Instrumentation was done on the samples but were not obturated. External surface of the roots was coated with 2 layers of nail varnish including the apical area. This was done to validate the ability of the nail varnish to seal the root surfaces against dye penetration.

All samples except negative control were then coated with 2 coats of nail varnish (Medora Swiss), except for the apical area $(2 \mathrm{~mm})$ that was left so that the tracer could penetrate the canal through the apical region. Samples were immersed in $2 \%$ aqueous methylene blue dye (MBD) solution (MERCK) and incubated (Memart) at $37^{\circ} \mathrm{C}$ for 1 week.

\section{Measurement of Dye Leakage}

Longitudinal grooves were done on both sides of each tooth root and they were sectioned. Diamond disc (Noritake Dental Supply Co. Ltd) with continuous cooling with distilled water was used for the sectioning. Each sectioned root was inspected under stereomicroscope (Motic DMW 143, PAL System, Hong Kong) at $15 x$ magnification with a calibrated ocular scale to assess apical microleakage. Motic image plus 2.0 ML software was used for measured longevity of dye leakage between gutta-percha and wall of the root canal from apex of root in value of millimeter. The degree of micro leakage was determined by calculating the vertical MBD penetration in millimeters $(\mathrm{mm})$ from the apical end to the maximum extent in coronal direction (apical leakage testing). Two assessors were used to determine apical leakage in order to eliminate bias. To eliminate bias, apical leakage of methylene blue dye was measured independently by two evaluators and the final values recorded were the arithmetic means of the measures obtained by the two accessors. Stereomicroscope (Motic DMW 143, PAL system, Hong Kong) was used to calculate all measurements at $40 x$ magnification with a standardized ocular scale. Motic Image Plus 2.0 ML software was used to determine longevity of DP between GP and walls of root canal apex in millimeters. The mean values of the two measurements were recorded.

The methylene blue dye penetration grading system was adopted and modified from Kytridou, Gutmann, Nunn ${ }^{9}$ as below (Table I).

TABLE I: MBD PENETRATION GRADING SYSTEM

\begin{tabular}{cl}
\hline GRADING & \multicolumn{1}{c}{ MBD PENETRATION } \\
\hline 0 & No penetration of dye \\
\hline 1 & $\begin{array}{l}\text { Penetration of dye from apical foramen } \\
\text { extending coronally: } 0.1 \mathrm{~mm}-1.0 \mathrm{~mm}\end{array}$ \\
\hline 2 & $\begin{array}{l}\text { Penetration of dye from apical foramen } \\
\text { extending coronally: }>1.1 \mathrm{~mm}-2.0 \mathrm{~mm}\end{array}$ \\
\hline 3 & $\begin{array}{l}\text { Penetration of dye from apical foramen } \\
\text { extending coronally: }>2.1 \mathrm{~mm}-3.0 \mathrm{~mm}\end{array}$ \\
\hline 4 & $\begin{array}{l}\text { Penetration of dye from apical foramen } \\
\text { extending coronally: }>3.1 \mathrm{~mm}-4.0 \mathrm{~mm}\end{array}$ \\
\hline 5 & $\begin{array}{l}\text { Penetration of dye from apical foramen } \\
\text { extending coronally: }>4.1 \mathrm{~mm}-5.0 \mathrm{~mm}\end{array}$ \\
\hline 6 & $\begin{array}{l}\text { Penetration of dye from apical foramen } \\
\text { extending coronally: }>5.1 \mathrm{~mm}-6.0 \mathrm{~mm}\end{array}$ \\
\hline 7 & $\begin{array}{l}\text { Penetration of dye from apical foramen } \\
\text { extending coronally: }>6.1 \mathrm{~mm}-7.0 \mathrm{~mm}\end{array}$ \\
\hline
\end{tabular}

SPSS version 16.0 (SPSS, Inc, USA) was used for statistical analysis. Descriptive analysis was determined as mean \pm standard deviation for dye leakage (DL) of each experimental group. Rate of recurrence and percentages were calculated for each experimental group according to above mentioned grading system (Table I). One Way ANOVA was used to compare the difference in mean DL. Bonferroni test was utilized to perform Post Hoc analysis. The level of significance was set at 0.05 .

\section{RESULTS}

The negative controls showed no DP, while the positive controls revealed full leakage throughout the length of the canal at 7-day period. Mean and standard deviation for DP of different groups was; Group A $2.02 \mathrm{~mm}(\mathrm{SD} \pm 0.86)$, Group B $2.17 \mathrm{~mm}$ $(\mathrm{SD} \pm 0.90)$ and Group C 2.67mm (SD \pm 1.17 ) (Table II). Group A and group B difference was statistically insignificant $(p=0.586)$ but in comparison to group C it was significant $(p=0.000)$ (Table II). The proportions of teeth with several grades of DP is shown in (Table III). Grade 5 DP was seen in few cases $(12.8 \%)$ in group C.

In most specimens, DP occurred at the interface between sealer and dentinal wall. However, some samples displayed dye leakage throughout the mass of the sealer. 
An In-Vitro Comparison and Analysis of Apical Microleakage of Thermafil

TABLE II: MEAN DYE DEPTH PENETRATION COMPARISON

\begin{tabular}{lccccc}
\hline Groups & $\begin{array}{c}\text { Samples } \\
\text { Number }\end{array}$ & $\begin{array}{c}\text { Total } \\
\text { Mean }( \pm \text { S.D) } \\
(\mathbf{m m})\end{array}$ & Range & P value \\
\cline { 1 - 4 } Group A & 78 & $2.02( \pm 0.86)$ & $0.5-3.5$ & \\
\cline { 1 - 4 } Group B & 78 & $2.17( \pm 0.90)$ & $0.7-4.0$ & 0.000 \\
\cline { 1 - 4 } Group C & 78 & $2.67( \pm 1.17)$ & $0.8-4.5$ & \\
\cline { 1 - 4 } & & & &
\end{tabular}

Significance level $-P<0.05$

TABLE III: PROPORTION OF TEETH WITH NUMEROUS GRADES OF DP

\begin{tabular}{|c|c|c|c|c|c|c|c|c|}
\hline Groups & $\begin{array}{c}\text { Grade } \\
0\end{array}$ & $\begin{array}{c}\text { Grade } \\
1\end{array}$ & $\begin{array}{c}\text { Grade } \\
2\end{array}$ & $\begin{array}{c}\text { Grade } \\
3\end{array}$ & $\begin{array}{c}\text { Grade } \\
4\end{array}$ & $\begin{array}{c}\text { Grade } \\
5\end{array}$ & $\begin{array}{c}\text { Grade } \\
6\end{array}$ & $\begin{array}{c}\text { Grade } \\
7\end{array}$ \\
\hline $\begin{array}{c}\text { Group A } \\
(n=78)\end{array}$ & -- & $\begin{array}{c}15 \\
19.2 \%\end{array}$ & $\begin{array}{c}16 \\
20.5 \%\end{array}$ & $\begin{array}{c}37 \\
47.4 \%\end{array}$ & $\begin{array}{c}10 \\
12.8 \%\end{array}$ & -- & - & -- \\
\hline $\begin{array}{c}\text { Group B } \\
(n=78)\end{array}$ & -- & $\begin{array}{c}6 \\
7.69 \%\end{array}$ & $\begin{array}{c}32 \\
41.0 \%\end{array}$ & $\begin{array}{c}23 \\
29.4 \%\end{array}$ & $\begin{array}{c}17 \\
21.7 \%\end{array}$ & -- & -- & -- \\
\hline $\begin{array}{c}\text { Group C } \\
(n=78)\end{array}$ & -- & $\begin{array}{c}16 \\
20.5 \%\end{array}$ & $\begin{array}{c}8 \\
10.2 \%\end{array}$ & $\begin{array}{c}19 \\
24.3 \%\end{array}$ & $\begin{array}{c}25 \\
32.1 \%\end{array}$ & $\begin{array}{c}10 \\
12.8 \%\end{array}$ & -- & -- \\
\hline
\end{tabular}

\section{DISCUSSION}

The present study evaluated sealing ability of different obturation techniques. TF system demonstrated lower leakage than System B. Thermafil obturation technique may have adapted well to the canal walls resulting in lower microleakage $^{10}$. However, it displayed DP, due to probable mass shrinkage of GP after cool down. CLC demonstrated greater microleakage in comparison TF and System B. This could be due to better sealing ability of $\mathrm{AH}$ Plus sealer. Moreover, $\mathrm{AH}-\mathrm{Plus}$ swells slightly during setting in liquid environment ${ }^{11}$. CLC exhibited maximum apical leakage, this finding was consistent with other studies ${ }^{11}$. This could be the result of the following factors: poor wettability of dentin, lack of leak-free seal between GP particles and $\mathrm{AH}$ Plus, and absence of chemical union between GP particles and master cone ${ }^{12}$. This study demonstrated that Thermafil provides a better seal in comparison to CLC and System B technique. However, more studies are required for assessing sealing ability of system B.

CLC group C demonstrated greatest leakage while Thermafil and system B showed less leakage. Results of other studies ${ }^{2,4,13,14}$ are consistent with our findings. DP difference was

statistically insignificant $(P$ value $=0.586)$ between Thermafil and System B. Studies have demonstrated that Thermafil obturation technique in -vitro is equivalent to warm vertical compaction as it achieves good 3-D filling resulting in fewer voids and replicating root surfaces ${ }^{15}$. However, further studies are required to confirm these findings on curved canals. Although, an apical seal is valuable but it is insufficient to ensure the long-term success of endodontic treatment. Results from System B has shown to produce endodontic fillings consisting of $>90 \%$ GP without modification of the temperature of the external root surface ${ }^{16}$. In contrast to our findings, a study found less leakage in roots obturated with cold lateral condensation in comparison to the warm vertical technique ${ }^{17}$. This difference could be attributed to different experimental conditions.

In this study, saline was used as a storage medium as chemical and physical properties of dentin are not altered by saline. The DP method was used due to its ease of use and lesser requirement of highend materials ${ }^{18}$. MBD was used as it has similar molecular size to bacterial by-products such as butyric acid (BA) which leaks out of diseased root canals to exacerbate the periapical tissues ${ }^{18}$.

Several studies ${ }^{20-22}$ have assessed the quality of apical seal obtained by different root canal obturation techniques by using various methods such as;

i) Radioisotope and dye penetration

ii) Fluid filtration

iii) Fluorometric and electrochemical means

iv) Gas chromatography

v) Scanning electron microscope

vi) Bacterial leakage

Some studies ${ }^{9,19}$ have compared lateral compaction obturation technique with other root canal obturation techniques with inconsistent results. Abarca AM $2001^{21}$ found no significant difference between CLC and thermomechanical compaction. Study conducted by Pommel $L 2001^{20}$ showed that lateral condensation is as effective as Thermafil, System B and vertical condensation in sealing the apex. However, after 1month lateral condensation exhibited higher apical leakage. Schafer E $2002^{22}$ found System B as effective as vertical condensation and Thermafil. Our study showed that all above mentioned obturation techniques provided an effective apical seal that decreased slightly with time. These findings were consistent with Yared G $1995^{19}$ who demonstrated a constant increase in apical microleakage over time This study was not without its limitations;

1. Dye Penetration method used only provided 
qualitative data of linear measurement of tracer penetration and it did not provide any information about the volume of the tracer penetration.

2. Only single rooted extracted teeth with straight canals were part of this study.

More longitudinal studies are required to evaluate leakage by using bacteria, dyes and radioisotopes. Further experiments should also be performed to evaluate bio-mechanical aspects of materials

The present study addressed a relevant research question regarding the decision making of root canal obturation of single rooted teeth. We recommend TF as a preferred technique to obturate single rooted teeth.

\section{CONCLUSION}

It can be concluded that all obturation techniques showed apical leakage. However, roots obturated with cold lateral condensation exhibited greater amount of leakage while Thermafil exhibited the least leakage.

Ethical permission: CPSP Synopsis Approval Letter No. CPSP/REU/DSG-2009-217-704. Dated 6-62011.

\section{Conflict of Interest: No any conflict of interest}

Funding: This research did not receive any grant

\section{REFERENCES}

1. Jindal $D$, Sharma $M$, Raisingani $D$, Swarnkar $A$, Pant M, Mathur R. Volumetric analysis of root filling with cold lateral compaction, Obtura II, Thermafil, and Calamus using spiral computerized tomography: An in vitro Study. Indian J Dent Res. 2017; 28(2): 175-80. doi: 10.4103/0970-9290.207785.

2. Nicastro KS, Prado M, Gomes BP, Ferraz C, Zaia AA, de Almeida JF. Influence of tapered gutta-percha master points and two instrumentation techniques on apical microleakage and root-filling material adaptation. Int J Clin Dent. 2017; 10(4): 237-46.

3. Libonati A, Montemurro E, Nardi R, Campanella V. Percentage of Gutta-percha-filled Areas in Canals Obturated by 3 Different Techniques with and without the Use of Endodontic Sealer. J endod. 2018; 44(3): 506-9. doi: 10.1016/j.joen. 2017.09.019.

4. Eroğlu MG, Bayırlı GŞ. The comparison of dentin adaptation and sealing ability of guttapercha/AH Plus, Resilon/Epiphany SE, Endo REZ: an in-vitro study. Eastern J Med. 2017; 22 (4): 155-61. doi:10.5505/ejm.2017.86580.

5. Kulkarni G, Balakrishnan R, Shetty $\mathrm{HH}$, Geetha P. A Quantitative Evaluation of the Sealing Ability of Three Different Obturation Techniques Using the Glucose Leakage Test: An In Vitro Study. J Int Oral Health. 2016; 8(7): 787-94. doi:10.2047/jioh-08-07-09.

6. Aggarwal C, Bahuguna N, Anand S, Manan R, Puri N. Comparative Evaluation of GuttaPercha Sealing Ability at the Apical 3rd Using Two Different Core Based Thermal Obturation Systems. Endodontology. 2015; 27(1): 33-7.

7. Jafari $F$, Jafari $S$. Importance and methodologies of endodontic microleakage studies: A systematic review. J Clin Exp Dent. 2017; 9(6): e812-e819.doi:10.4317/jced.53604.

8. Moradi S, Lomee $M$, Gharechahi $M$. Comparison of fluid filtration and bacterial leakage techniques for evaluation of microleakage in endodontics. Dent Res J (Isfahan). 2015; 12(2): 109-14.

9. Kytridou V, Gutmann JL, Nunn MH. Adaptation and seal ability of two contemporary obturation techniques in the absence of the dentinal smear layer. Int Endod J. 1999; 32(6): 464-74. doi: 10.1046/j.1365-2591.1999.00248.x.

10. Ho ES, Chang JW, Cheung GS. Quality of root canal fillings using three gutta-percha obturation techniques. Restor Dent Endod. 2016; 41(1): 22-8. doi: 10.5395/rde.2016.41.1.22

11. Bahuguna N, Kapoor N. Comparison of canal volume sealing capacity at different levels from the root apex using various cold and thermal obturating techniques: An in vitro study. Endodontology. 2017; 29(2): 101-6. doi:10.4103/ endo.endo_27_17

12. Marques-Ferreira $M$, Abrantes $M$, Ferreira HD, Caramelo F, Botelho MF, Carrilho EV. Sealing efficacy of system B versus Thermafil and Guttacore obturation techniques evidenced by scintigraphic analysis. J Clin Exp Dent. 2017; 9 (1): e56-e60. doi: 10.4317/jced.52889

13. Neuhaus KW, Schick A, Lussi A. Apical filling characteristics of carrier-based techniques vs. single cone technique in curved root canals. Clin oral investig. 2016; 20(7): 1631-7. doi: 10.1007/ s00784-015-1674-2.

14. Bansal G, Bansal A, Padda B. An In Vitro comparison of the apical seal produced by three different thermoplasticized Guttapercha obturation techniques in oval canals. Dent J Adv Studies. 2015; 3: 39-46. doi:10.1055/s-00381672012.

15. Soo WK, Thong YL, Gutmann JL. A comparison of four gutta-percha filling techniques in simulated C-shaped canals. Int Endod J. 2015; 48(8): 736-46. doi: 10.1111/iej.12371.

16. Suguro $H$, Takeichi $O$, Hayashi $M$, Okamura $T$, Hira A, Hirano $Y$, et al. Microcomputed tomographic evaluation of techniques for warm Gutta-Percha obturation. J Oral Sci. 2018; 60 (2): 165-69. doi:10.2334/josnusd.17-0092.

17. Lone MM, Khan FR. Evaluation of micro leakage of root canals filled with different 
obturation techniques: An in vitro study. J Ayub Med Coll Abbottabad. 2018; 30(1): 34-9.

18. Sinhal TM, Shah RR, Jais PS, Shah NC, Hadwani KD, Rothe $T$, et al. An In vitro comparison and evaluation of sealing ability of newly introduced c-point system, cold lateral condensation, and thermoplasticized guttapercha obturating technique: $A$ dye extraction study. Contemp Clin Dent. 2018; 9(2): 164-9. doi:10.4103/ccd.ccd_722_17.

19. Yared G, Dadher F. Influence of plugger penetration on the sealing ability of vertical condensation. J Endod. 1995; 21(3): 152-3. doi: 10.1016/s0099-2399(06)80442-5.
20. Pommel L, Camps J. In vitro apical leakage of System B compared with other filling techniques. J Endod. 2001; 27(7): 449-51. 10.1097/00004770$200107000-00003$.

21. Abarca AM, Bustos A, Navia M. A comparison of apical sealing and extrusion between Thermafil and lateral condensation techniques. J Endod. 2001; 27(11): 670-2. doi:10.1097/0000470200111000-00004.

22. Schafer E, Olthoff G. Effect of three different sealers on the sealing ability of both thermafil obturators and cold laterally compacted guttapercha. J Endod. 2002; 28(9): 638-42. doi:10.1097/00004770-200209000-00003.

AUTHOR AFFILIATION:

Dr. Noor-ul-Ain Jawaed (Corresponding Author)

Assistant Professor

Department of Operative Dentistry

Dr. Ishrat-ul-Ebad Khan Institute of Oral Health Sciences (DIKIOHS)

Dow University of Health Sciences (DUHS)

Karachi, Sindh-Pakistan.

Email: noorulain.jawaed@duhs.edu.pk

dr_noorulainkhurram@yahoo.com

\section{Prof. Syed Yawar Ali Abidi}

Professor, Department of Operative Dentistry

Sindh Institute of Oral Health Sciences

Jinnah Sindh Medical University (JSMU)

Karachi, Sindh-Pakistan.

\section{Dr. Muhammad Imran Khan Niazi}

Senior Associate, Lumino the dentist

Palmerston North, New Zealand.

\section{Dr. Khurram Parvez}

Associate Professor, Dental Materials,

Dr. Ishrat-ul-Ebad Khan Institute of Oral Health Sciences DIKOHS

Dow University of Health Sciences, DUHS

Karachi, Sindh-Pakistan.

\section{Prof. Farah Naz}

Professor, Operative Dentistry

Dental section, Dow International Medical College DIMC

Dow University of Health Sciences, DUHS

Karachi, Sindh-Pakistan.

\section{Dr. Shahbaz Ahmed}

Associate Professor, Operative Dentistry

Dr. Ishrat-ul-Ebad Khan Institute of Oral Health Sciences (DIKIOHS)

Dow University of Health Sciences (DUHS)

Karachi, Sindh-Pakistan. 